\title{
O uso do solo e a participação das atividades de comércio e de serviços no centro da cidade
}

\section{The land use and the participation of commercial and service activities in the city center}

\author{
Denise de Cassia Rossetto Januzzi ${ }^{1}$; Ulysses Amarildo Januzzi ${ }^{2}$; Nestor Razente ${ }^{3}$
}

\section{Resumo}

Este texto tem por objetivo mostrar como as atividades do setor terciário se distribuem espacialmente na área central da cidade de Londrina. Para obter as informações, levantamos o uso e a ocupação do solo no centro da cidade, comparando-os com os dados existentes da década de 1990. A pesquisa demonstrou que o perímetro do centro urbano foi ampliado e que as atividades comerciais se intensificaram em algumas regiões. Os resultados obtidos foram mapeados e pudemos verificar como essas atividades e serviços se expandiram. Foi possível também compreender melhor a dinâmica do uso e da ocupação do solo na área escolhida para o estudo.

Palavras-chave: Urbanismo. Uso do solo. Comércio. Serviços.

\begin{abstract}
This paper aims to show how the activities of the tertiary sector are distributed in city center and therefore within the city of Londrina. To obtain more information the city's center land use and occupation was studied and compared with the 90 's existing data. The research showed that the urban center's perimeter was enlarged and that the activities were intensified in some regions. The obtained results were mapped permitting to verify how commercial activities and services have expanded. It was also possible to better understand the dynamics of land use and occupation in the studied area.
\end{abstract}

Keywords: Urban planning. Land use. Commerce. Services

\section{Introdução}

Os espaços urbanos centrais atravessam um processo de mudança em decorrência das transformações sociais e das atividades de comércio e serviços. Entre as principais mudanças, estão a busca da população por bairros mais afastados e os novos formatos comerciais como shopping centers e hipermercados, geralmente implantados em grandes

\footnotetext{
${ }^{1}$ Arquiteta, professora e pesquisadora da Universidade Estadual de Londrina - DAU-UEL. Mestre e Doutora pela FAU-USP Email: deniserj@uel.br. Coordenadora do projeto de pesquisa.

${ }^{2}$ Administrador, professor e pesquisador da UNOPAR. Mestre pela UEL. Email: ulyssesj@hotmail.com

${ }^{3}$ Arquiteto, professor e pesquisador da Universidade Estadual de Londrina- DAU- UEL. Lic. em filosofia, mestre pela UFP e doutora pela FAU-USP. Email: nrazente@gmail.com
} 
áreas urbanas, dispondo de amplos estacionamentos gratuitos e de fácil acesso a vias rápidas e estradas principais. Este tipo de desenvolvimento comercial periférico pode resultar em algumas vantagens para o consumidor, mas para o centro comercial tradicional pode trazer alguns prejuízos econômicos, sociais e ambientais, com a queda nas vendas no varejo e o abandono da população das áreas centrais. Para Jacobs (2001, p. 181) a região central costuma ser o coração de uma cidade, "quando o coração urbano para ou se deteriora, a cidade, enquanto conjunto de relações sociais, começa a sofrer: as pessoas que deveriam se encontrar deixam de fazê-lo, em virtude da falta de atividades do centro", essa troca de produção e consumo deixa de acontecer diminuindo a vitalidade dos centros urbanos, fazendo com que a estrutura da vida pública urbana sofra rupturas insustentáveis. Na intenção de buscar subsídios para manter e reforçar o tecido urbano da área central e as atividades nele existentes, esse trabalho busca esclarecer as contribuições que o setor terciário traz para o centro das cidades.

\section{O município de Londrina e o centro da cidade}

A pesquisa foi desenvolvida na cidade de Londrina, localizada no norte do Paraná e fundada na década de 1920, sendo que as primeiras ocupações ocorreram nas proximidades dos principais acessos da cidade, nas ruas Duque de Caxias e Celso Garcia Cid, onde se estabeleceram residências, mercados e hotéis.

Atualmente, o centro situa-se na malha inicial projetada, ou seja, onde aconteceram as primeiras ocupações (Figura 1). Trata-se de um lugar importante, pois nele existe uma grande quantidade e diversidade de atividades de gestão pública, serviços, prédios comerciais e residenciais. Nele localizam-se também os terminais de transportes intraurbanos e interurbanos.
Figura 1 - Centro da cidade de Londrina.

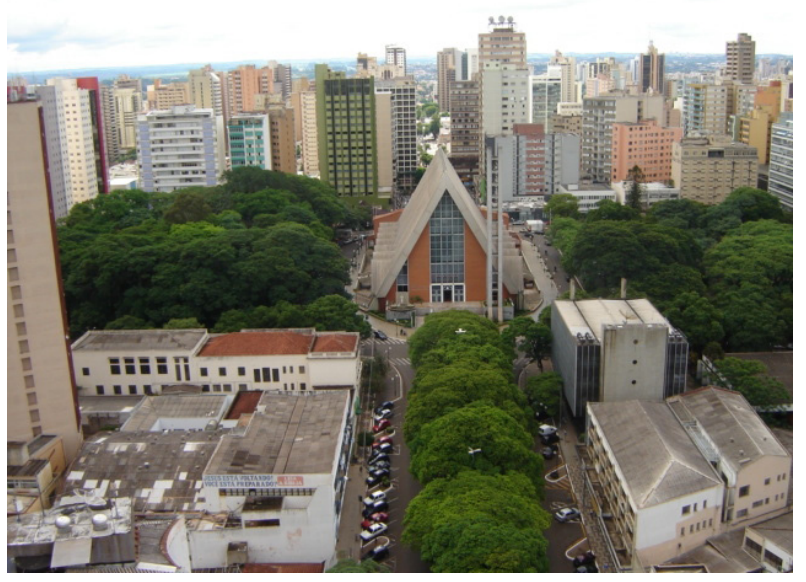

Fonte: panoramio.com.photo, 2011.

De acordo com o último censo do IBGE (2010), o município de Londrina possui atualmente 506.645 habitantes. Entretanto, é importante percebermos as características geodemográficas da região, formada pelas cidades circunvizinhas à cidade de Londrina, para entendermos a dinâmica do fluxo diário nas ruas e no comércio da cidade, que englobam a população e a força econômica dessa malha urbana formada, transformando a cidade de Londrina em um importante centro de serviços e comércio do interior do Paraná. Essa malha urbana contínua polarizada pela cidade de Londrina, é formada pela população das cidades de Arapongas, Cambé, Ibiporã, Jataizinho, Rolândia e Londrina, chegandose a uma população de 825.470 habitantes, de acordo com o senso da população das cidades informado pelo IBGE (2010).

A importância estratégica dessa região assume uma posição de destaque quando se analisa o potencial econômico dessa região, cujo poder médio de compra por habitante - aferido através do PIB per capita/ano - atinge uma cifra aproximada de R $\$$ $17.000,00$ ao ano, ficando em torno de $7 \%$ acima da média nacional, cuja estimativa (IBGE, 2010) é de 
aproximadamente $\mathrm{R} \$ 15.900,00$. É essa população que influencia diretamente no fluxo econômico terciário da cidade, afetando por consequência o fluxo viário de suas ruas e avenidas em diferentes dimensões que se caracterizam principalmente pelo perfil sócio-econômico que predomina, tanto a população residencial como os estabelecimentos do comércio e serviços da região.

Os setores de comércio e serviços envolvem também relações sociais, que fazem parte do cotidiano e da história da nossa civilização, conforme Vargas (2001), ao concluir que a troca tem um caráter social porque nela é indispensável o encontro entre as pessoas, os bens e serviços a serem comercializados para que o negócio seja realizado.

A cidade conta ainda com uma boa infraestrutura básica que subsidia um significativo fluxo de turistas que incrementa a economia do município, atraído por uma movimentada agenda de festivais de música, de teatro, congressos, seminários e da exposição agropecuária anual.

\section{Os setores da economia de um país}

Figura 2 - Cidade de Londrina

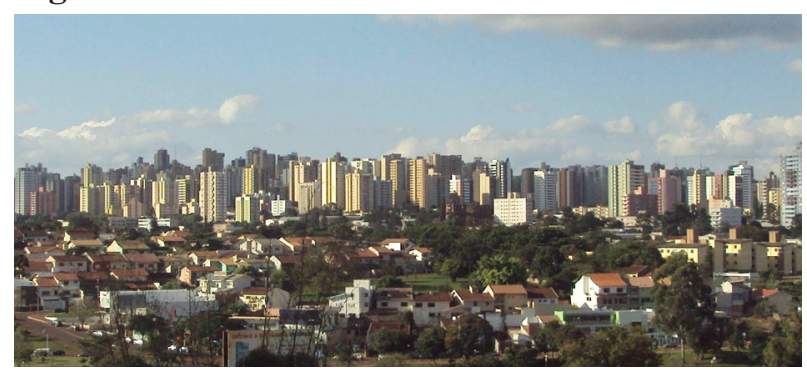

Fonte: Foto do autor, 2011.

Os principais órgãos de estudos econômicos de todo o mundo elencam em consenso, para efeito de estudos, a divisão da economia de um país em setores: primário, secundário e terciário. Através desse critério, a análise dos setores é capaz de mostrar o grau de desenvolvimento econômico de um país ou região.

O Setor Primário está relacionado à geração de recursos através da extração e exploração de recursos da natureza, representado basicamente pelas atividades agrícolas, de mineração, caça, pesca e criação de animais. Portanto, é esse setor da economia que fornece a matéria-prima tangível para a indústria de transformação.

OSetor Secundário é responsável por transformar todo o tipo de matéria-prima (produzida pelo setor primário) em produto com valor agregado através das indústrias. Geralmente, o processo de transformação necessita de aplicação de tecnologia, pesquisa e conhecimento, competências essas de elevado valor agregado. Por essa característica o setor secundário caracteriza-se como grande de riquezas e empregos - tanto direto como indireto - de qualificação superior aos demais setores da economia.

O Setor Terciário está o relacionado aos serviços e entende-se por serviços o produto final intangível gerado pelo esforço de pessoas ou empresas, para satisfazer as necessidades e desejos de terceiros. Isso faz desse setor o mais complexo e abrangente dos três citados, envolvendo basicamente as seguintes atividades econômicas: comércio, educação, saúde, telecomunicação, serviços de informática, serviços de entretenimento, seguros, transporte, serviços de limpeza, turismo, serviços bancários, contábeis, administrativos, etc.

Com o processo de globalização iniciado no século XX e acelerado exponencialmente a partir deste século, o setor terciário é o que mais se destaca nos indicadores das principais potências econômicas mundiais. O estágio de globalização em que o mundo vivencia é uma realidade inescapável, principalmente quando nos reconhecemos como os protagonistas dessa condição, onde a evolução constante da tecnologia, da informação e da comunicação (TIC) aliada à - igualmente constante - evolução dos meios tangíveis de transporte. 
Todo esse progresso tem acirrado a concorrência econômica em escala mundial e, por consequência, gerando novas atividades econômicas que integram em seus produtos, atividades dos três setores da economia, principalmente os setores secundários e terciários. O aumento da complexidade das atividades econômicas tem causado crescentes divergências em sua classificação por parte dos estudiosos do setor, quanto a sua natureza econômica.

O comércio, por exemplo, é caracterizado basicamente pela atividade de entregar produtos tangíveis de todos os tipos ao consumidor onde o prestador de serviço cobra por essa atividade. Entretanto, a crescente concorrência nesse segmento da economia, agravada pela globalização, tem levado o setor de comércio a diferenciar o seu serviço em relação aos seus concorrentes, através de atendimento personalizado, entrega em domicílio, diferentes canais de atendimento, e-commerce e da entrega de produtos agregados ao pacote, tanto tangíveis quanto intangíveis, tais como garantia estendida e itens opcionais. Em resumo, a atividade comercial - tão simples de outrora - tem se tornado uma atividade cada vez mais complexa, à qual se agregam atividades de logística, serviços especializados, informática e, muitas vezes, atividades de transformação física.

Outro exemplo dessa complexidade é o relativamente novo segmento de tecnologias da informação. As empresas, taxadas inicialmente de prestadoras de serviço de desenvolvimento de sistemas e programas informatizados, hoje são conhecidas como indústrias de software. Uma justa nomenclatura, já que essas empresas literalmente produzem produtos de elevado valor agregado que, embora intangíveis, são comercializados em lojas físicas e virtuais no mundo inteiro. A complexidade de se classificar adequadamente essas atividades é tão grande que tem causado polêmica até na maneira correta de se cobrar impostos dessas atividades, por parte dos órgãos públicos.

As atividades econômicas que englobam o setor terciário são atualmente mais marcantes nos países de alto grau de desenvolvimento econômico. Em geral, as estatísticas comprovam que, quanto mais rica é uma região, maior é a presença de atividades desse setor. No Brasil os indicadores dos três setores da economia que formam o seu Produto Interno Bruto (PIB) também indicam essa tendência, como demonstram os dados, de acordo com as informações oficiais do governo (PORTAL BRASIL, 2010).

Setor Primário: Responsável por $27 \%$ do PIB, 42,5\% das exportações totais em 2009 e mais de 17 milhões de empregos. Além disso, o país é fornecedor de $25 \%$ do mercado mundial de alimentos, fazendo com que o Brasil seja conhecido internacionalmente como um país fornecedor de matéria-prima aos países industrializados.

Setor Secundário: Em 2008, a indústria foi responsável por $27,9 \%$ do PIB e pelo emprego de $17,6 \%$ da população economicamente ativa.

Setor Terciário: Responde atualmente por mais da metade do PIB brasileiro, aproximadamente $55 \%$. Por essa razão, é atualmente o setor que mais gera postos de trabalho, com quase $75 \%$ dos empregos do país.

\section{As classes socioeconômicas do Brasil}

Atualmente podemos encontrar diferentes critérios de classificação socioeconômica da população brasileira. Com o propósito de viabilizarmos os estudos que se desenvolvem no presente artigo, optamos pela adoção do seguinte critério de classificação das classes socioeconômicas:

Classe alta: Famílias com renda mensal acima de 20 salários mínimos.

Classe média-alta: Famílias com renda mensal entre 10 e 20 salários mínimos. 
Classe média: Famílias com renda mensal entre 5 e 10 salários mínimos.

Classe média-baixa: Famílias com renda mensal entre 3 e 5 salários mínimos.

Classe baixa: Famílias com renda mensal abaixo de 3 salários mínimos.

A importância estratégica da região estudada se acentua quando a análise parte para o seu potencial econômico. De acordo com estimativas do IBGE (2011), a população da cidade de Londrina possui uma renda per capita/ano de aproximadamente $\mathrm{R} \$$ $17.000,00$, sendo que a população da malha urbana da região mantém a mesma média de renda per capita/ ano.

Essa renda média per capita/ano está dentro da média do estado do Paraná e acima da média nacional aferida em aproximadamente $\mathrm{R} \$$ $16.000,00$.

\section{A pesquisa sobre as atividades comerciais e de serviços no centro de Londrina}

$\mathrm{Na}$ pesquisa, o critério utilizado para delimitar o centro de Londrina, foi o elaborado por Villaça (1998), determinando seu perímetro. De acordo com a teoria, os limites são estabelecidos nos lugares onde existe mais de $50 \%$ de áreas comerciais e de serviços ocupadas em um quarteirão. Segundo Januzzi (2000), o centro principal foi caracterizado especialmente pelo tipo de comércio existente, especialmente por um comércio bem diversificado, pela existência lojas grandes e médias, de bancos, restaurantes, hotéis, escolas não oficiais, repartições públicas e de outros serviços.

No primeiro levantamento representado pela década 1980, o centro apresenta-se nas imediações da igreja matriz, estendendo-se pelas vias de grande fluxo da época, como a Rua Quintino Bocaiúva e Duque de Caxias, que faziam as principais ligações da cidade com os municípios de Ibiporã, a leste, Cambé, a oeste e Curitiba, ao sul.

Os critérios de Villaça (1999) foram utilizados para delimitar o centro de Londrina em 1999, época em que a sua abrangência apresentava-se um pouco menor que atualmente. O centro localiza-se na área que compreende a malha inicial projetada da cidade, conforme mostra a Figura (3).

$\mathrm{Na}$ atualidade, o centro de Londrina (centro histórico e comercial/serviços) continua localizado na malha inicial projetada da cidade, conforme mostra a Figura (4), na qual está delimitado o perímetro, mas se expandiu nas bordas, apresentando um crescimento maior na região leste, conforme mostra o mapa da Figura (4).

Conforme artigo do Jornal de Londrina de 15/08/2011, na matéria "O Centro da Discórdia," o resultado da pesquisa pode auxiliar nas políticas públicas, visto que, com a aprovação da "Lei da Muralha" (Leis Municipal no 9.869/2005 e $10.092 / 2006)^{4}$, se estabelecem limites questionáveis sobre o perímetro do centro, que atualmente vai das avenidas Dez de Dezembro (Leste) à Maringá (Oeste), Brasília (Norte) à Portugal (Sul), portanto, muito além do que mostra o resultado da pesquisa.

$\mathrm{Na}$ verdade essa lei restringe a possibilidade de abrir novos empreendimentos na região central de Londrina, privilegiando o comércio já existente. $\mathrm{O}$ assunto polêmico foi parar na justiça com o argumento que atrapalha a livre concorrência e o desenvolvimento da cidade.

Neste sentido, a pesquisa vem contribuir para esclarecer qual seria o perímetro do centro de acordo com a teoria de Villaça, auxiliando nas políticas públicas.

\footnotetext{
4 As Leis Municipal no 9.869/2005 e 10.092/2006, determinam a proibição da instalação de supermercados com área maior que 1500 metros quadrados e lojas de materiais de construção acima de 500 metros quadrados.
} 
Figura 3 - Centro da cidade de Londrina em 1980 e 1999.

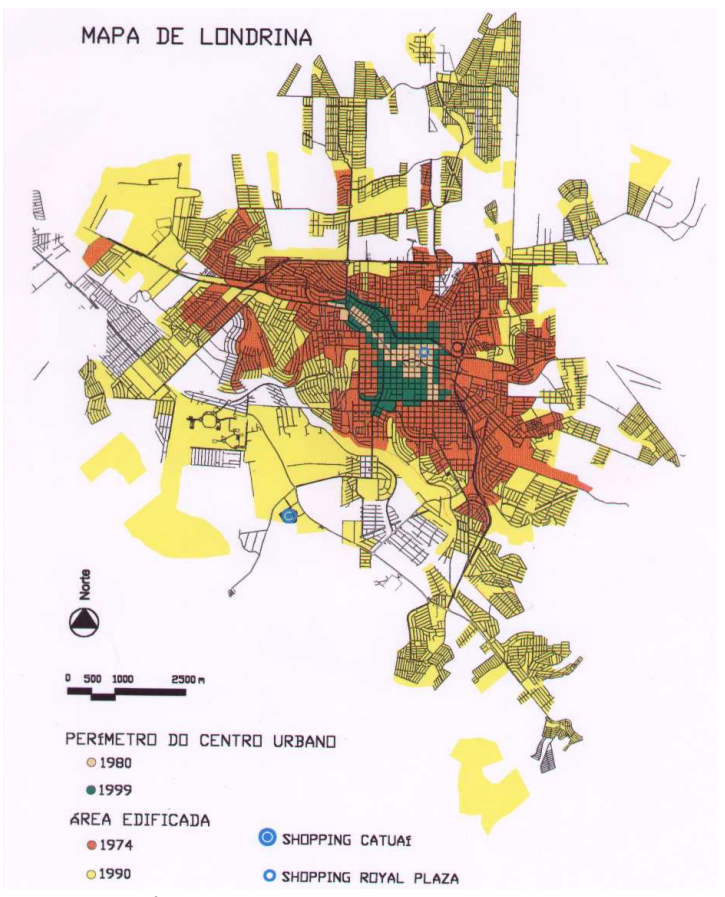

Fonte: Grassiotto, 2000.

$\mathrm{Na}$ atualidade, o centro de Londrina (centro histórico e comercial/serviços) continua localizado na malha inicial projetada da cidade, conforme mostra a Figura (4), na qual está delimitado o perímetro, mas se expandiu nas bordas, apresentando um crescimento maior na região leste, conforme mostra o mapa da Figura (4).

Conforme artigo do Jornal de Londrina de 15/08/2011, na matéria "O Centro da Discórdia," o resultado da pesquisa pode auxiliar nas políticas públicas, visto que, com a aprovação da "Lei da Muralha" (Leis Municipal no 9.869/2005 e $10.092 / 2006)^{5}$, se estabelecem limites questionáveis sobre o perímetro do centro, que atualmente vai das avenidas Dez de Dezembro (Leste) à Maringá (Oeste), Brasília (Norte) à Portugal (Sul), portanto, muito além do que mostra o resultado da pesquisa.

$\mathrm{Na}$ verdade essa lei restringe a possibilidade de abrir novos empreendimentos na região central de Londrina, privilegiando o comércio já existente.
O assunto polêmico foi parar na justiça com o argumento que atrapalha a livre concorrência e o desenvolvimento da cidade.

Neste sentido, a pesquisa vem contribuir para esclarecer qual seria o perímetro do centro de acordo com a teoria de Villaça, auxiliando nas políticas públicas.

Para Villaça (1998, p. 23), a localização:

é a relação a outros objetos ou conjuntos de objetos e a localização urbana é um tipo específico de localização: aquela na qual as relações não podem existir sem um tipo particular de contato: aquele que envolve deslocamentos dos produtores e dos consumidores entre os locais de moradia e produção de consumo.

Isso explica as ruas especializadas e os subcentros que estão localizados perto de seus consumidores, seja pela distância do centro ou por estar perto de alguma atividade vinculada aquele tipo de comércio.

Figura 4 - Mapa de uso do solo no centro da cidade de Londrina,com a delimitação do centro de acordo com os critérios abordados por Villaça.

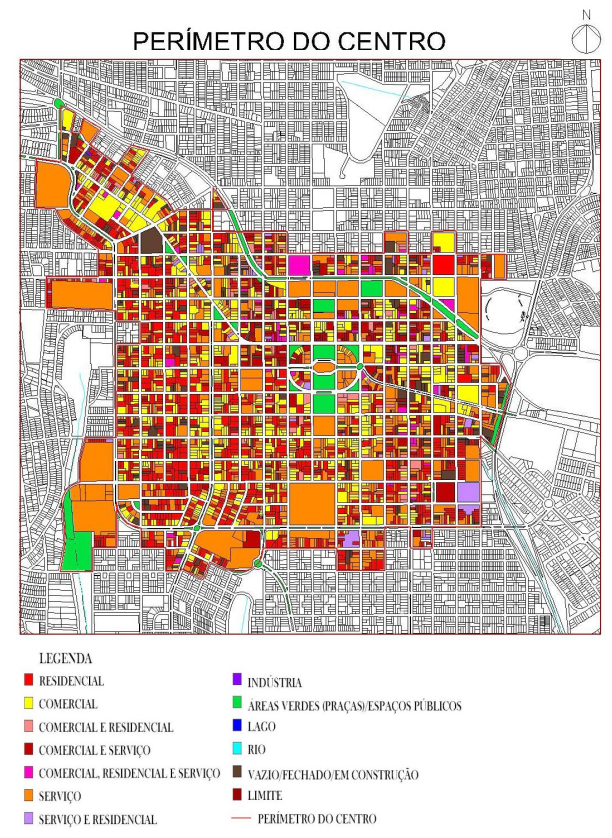

Fonte: Instituto de Pesquisa e Planejamento Urbano de Londrina. Elaboração do autor, 2011.

\footnotetext{
5 As Leis Municipal no 9.869/2005 e 10.092/2006, determinam a proibição da instalação de supermercados com área maior que 1500 metros quadrados e lojas de materiais de construção acima de 500 metros quadrados.
} 
Figura 5: Mapa do Centro da cidade de Londrina dividido em quadrantes.

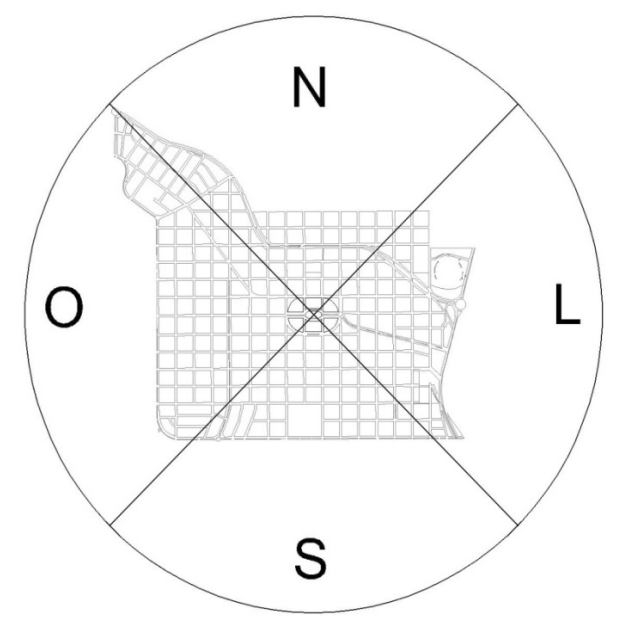

Fonte: IPPUL. Elaboração do autor, 2011.

Nas imediações da igreja matriz, ao norte existe uma maior concentração de uso misto, com comércio, serviços e residências no mesmo lote. Esse tipo de ocupação reforça a vitalidade do espaço, evitando a deterioração e o abandono do local conforme se observa que não ocorre no centro da cidade de Londrina.

Nessa área existe uma grande diversidade de atividades de lazer e cultura: como bibliotecas, teatros, praças, museus e escolas (públicas e particulares). Nela encontram-se também uma grande variedade de comércios e serviços como grandes lojas de varejo, loja de departamentos, agências bancárias, financeiras, eletrodomésticos, eletrônicos, vestuário, farmácias, padarias, magazines, hotéis, escritórios e órgãos públicos. Segundo Villaça (1998, p.49), a "atividade econômica apresenta um estreito relacionamento com o espaço físico que the dá suporte, criando o que chamamos de localização. Assim o processo de mudança econômica é ao mesmo tempo causa e efeito dos padrões sociais existentes".

Podemos observar que na estruturação da área central existe uma distribuição das atividades, onde nas imediações da rua de pedestres localizada na
Avenida Paraná, encontramos diversas agências bancárias, redes de lojas de departamentos e redes de lojas de eletroeletrônicos com perfil sofisticado. Já na Rua Sergipe, observa-se uma maior concentração de lojas de calçados e roupas destinadas a um consumidor de classe média. Na Rua Benjamin Constant, há uma concentração de lojas populares de eletroeletrônicos, móveis e utensílios domésticos, com forte identificação com o público mais popular.

Em meio às atividades predominantes de cada rua dessa região, encontra-se significativa diversificação de outras atividades como: bancos, restaurantes, lanchonetes e até hotéis, sempre com características que os identifica com o perfil do público que frequenta cada região.

Na região oeste existe uma maior concentração de residências, especialmente as multifamiliares, apresentando um alto adensamento com edificações de médio e alto padrão. Nesse lugar existe um comércio mais sofisticado com lojas de roupas, restaurantes, padarias, bares, joalherias, salões de beleza, supermercados, academias de ginástica, agências bancárias, templos religiosos, escolas de línguas estrangeiras, escolas e faculdades particulares.

Percebe-se uma tendência gradativa à sofisticação das atividades de comércio e serviços principalmente nas imediações da Avenida Higienópolis e, mais ainda, na região que fica entre a Avenida Higienópolis e a Avenida JK, formando um quadrilátero limitado, ao norte pela Rua Sergipe e ao sul também pela Avenida JK. Essa região localizada é conhecida e identificada pela classe dos imobiliaristas de Londrina como a Região dos Jardins de Londrina. Isso se deve ao fato de suas características, tanto geográficas como do público que habita este local, serem muito semelhantes ou lembrarem (guardando-se as devidas proporções) a região dos Jardins da cidade de São Paulo. Assim como a região dos Jardins de São Paulo, a Região dos Jardins de Londrina localiza-se estrategicamente bem próximo as facilidades do centro da cidade, ao mesmo tempo em que guarda características de região predominantemente residencial. Essa 
localização estratégica vem atraindo há algum tempo, investimentos imobiliários residenciais de alto padrão em forma de edifícios de amplos e sofisticados apartamentos. Em consequência disso, atividades de comércio e serviços sofisticados tem se estabelecido nessa região, tais como: a maior concentração de agências bancárias prime, restaurantes, joalherias e boutiques sofisticados, além de supermercados confeitarias e empórios da linha Premium. Também se encontram nessa região academias de fitness, lavanderias e escolas de idiomas direcionados ao público classe A. No alto da Avenida Higienópolis e suas imediações, bem como na Avenida JK - as duas grandes artérias dessa região - também se localizam hotéis de alto padrão, todos eles bem próximos a essa região conhecida como os Jardins de Londrina.

A parte leste apresenta em sua área comercial, atividades como lojas de tintas, móveis usados, eletro eletrônicos e venda de carros usados, apresentando um padrão inferior em relação à parte oeste, além de um segmento de comércio e serviços bem diversificado. Essa região apresenta também diversas instituições públicas de ensino como o IEEL (Instituto de Educação Estadual de Londrina) e Evaristo da Veiga, além de órgãos públicos como a Receita Federal, DER (Departamento de Estradas e Rodagem), COPEL (Companhia Paranaense de Energia) e a Delegacia da Mulher.

Neste lado da cidade existe uma grande declividade onde se localiza o Córrego das Pombas e a Avenida Dez de Dezembro, gerando uma barreira física limitadora para o crescimento da cidade nessa região.

Percebe-se nessa região uma dinâmica intensa atividade comercial e de serviços, com a forte presença do público das classes média e média-baixa. Isso se deve principalmente a três fatores que consolidaram a forte presença do público com esse perfil.

Em primeiro lugar, identifica-se a influência da rodoviária de Londrina, localizada na confluência das Avenidas Leste-Oeste e Dez de Dezembro, atraindo para aquela região investimento em hotelaria, comercio e serviços populares. Em segundo lugar temos a existência de serviços públicos populares como hospitais e clínicas municipais como o PAI (Pronto atendimento infantil) entre outros, todos localizados na Avenida Leste-Oeste, entre as Ruas Minas Gerais e Santa Catarina, garantindo presença constante de grande público das classes média e baixa na região. Em terceiro lugar é a presença de outra iniciativa da prefeitura da cidade em estabelecer na região, o Camelódromo de Londrina localizado na esquina da Rua Mato Grosso com a rua Sergipe que, por sua vez, acabou atraindo em suas imediações, outras pequenas galerias e atividades correlatas, consolidando o forte perfil popular das atividades profissionais dessa região.

O perfil de atividades populares da região central de Londrina se estende a partir dessa região pelas Ruas Sergipe até a Avenida Leste-Oeste, formando um corredor de atividades comerciais e de serviços voltadas ao público das classes médias e baixas, na região Norte da igreja matriz.

A identidade com esse público nessa região é fortalecida pela presença do terminal de transporte intra-urbano que se situa entre a Avenida LesteOeste e a Rua Benjamin Constant, bem próximo aos museus das antigas estações rodoviária e ferroviária da cidade. A localização do terminal nesse local é estratégica, pois facilita o deslocamento da população, proporcionando um fluxo intenso e constante de pessoas na região, fortalecendo investimentos em pequenos comércios e serviços na região, destinado e esse público.

Nessa área existe o camelódromo, que foi criado para abrigar os vendedores ambulantes que ficavam nas ruas do centro e atualmente é um lugar muito frequentado da região central, criando uma área de grande movimento de pessoas também por estar localizado nas proximidades do Shopping Royal Plaza, que é um local que atrai um grande público para compras, inclusive à noite. Nela existem diversas galerias comerciais que abrigam pequenas lojas de aproximadamente $30 \mathrm{~m} 2$. Esse tipo de comércio 
de pequeno porte se espalhou por diversas áreas da região central.

Ao sul da região central existe uma grande quantidade de serviços relacionados à saúde, dentre eles os hospitais de Olhos, Santa Casa, Hospital da Mulher e diversas clínicas médicas e odontológicas. A Rua Senador Souza Naves apresenta uma grande concentração de clínicas, possivelmente em função de a Santa Casa estar inserida neste local, o que atraiu outras atividades afins.

O cemitério São Pedro, o mais antigo da cidade, encontra-se na região sul, inicialmente nas suas imediações existiam marmorarias, mas esse tipo de comércio deu lugar a edifícios residenciais.

Em análise do perímetro definido no mapa do centro da cidade de Londrina, as áreas de comércio e serviços estendem-se por vias importantes no deslocamento da cidade, onde se observa grande fluxo, como a Av. Juscelino Kubistchek, Higienópolis, Quintino Bocaiúva, Fernando de Noronha, Souza Naves e Casoni (Figura 6). Isso ocorre geralmente pela localização privilegiada onde principalmente o comércio pode ser visto e acessado com facilidade.

Figura 6 - Mapa do Centro da Cidade de Londrina com os logradouros

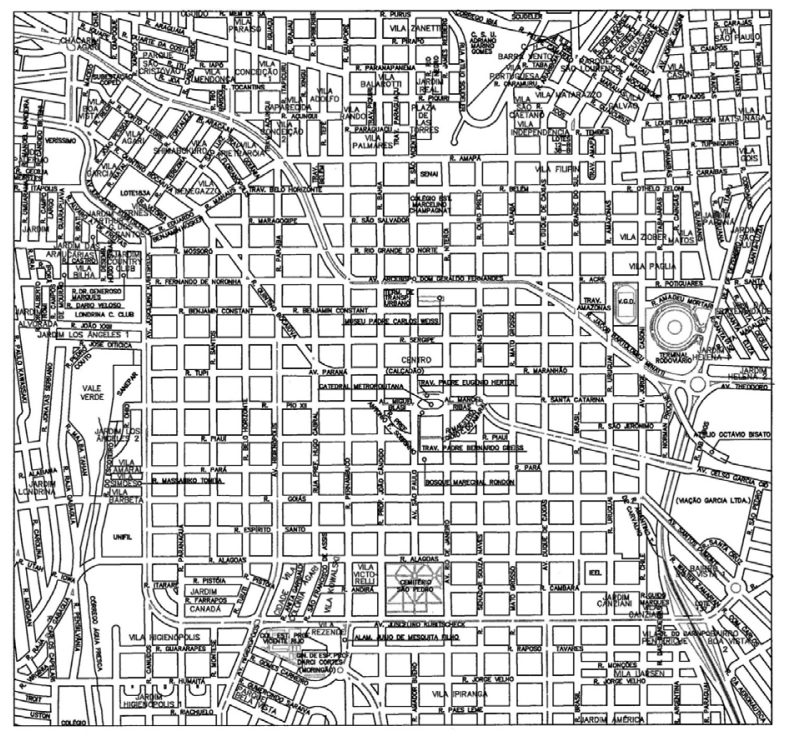

Fonte: IPPUL, elaboração do autor, 2011.

\section{Considerações finais}

Neste trabalho verificou-se que as atividades de comércio e serviços diversificadas acompanharam o crescimento da cidade, expandindo-se em direção ao mercado consumidor, especialmente nas vias principais. A região central foi se expandindo com o crescimento da cidade, e o setor de comércio e serviços seguiu em várias direções, pelas Avenidas Higienópolis e Madre Leônia Milito, para o Catuaí Shopping; pela Rua Quintino Bocaiúva, em direção a Cambé, e pela Avenida Dez de Dezembro, em direção a Ibiporã.

Podemos dizer ainda que na medida em que a cidade cresceu, algumas ruas comerciais foram se especializando, como a Rua Senador Souza Naves e a Avenida Bandeirantes, ocupadas por hospitais e clínicas; a Rua Guaporé e a Avenida Dez de Dezembro, com suas lojas de peças de carros; a Avenida Benjamim Constant, com lojas de móveis e eletrodomésticos, entre outras.

Como estamos falando de um setor da economia que gera muita renda e emprego, daí a importância da leitura da ocupação das atividades por áreas procurando estabelecer relações entre as atividades do setor terciário e os padrões de ocupação, buscando identificar características de acordo com o perfil do consumidor que frequenta cada região.

Esta pesquisa auxilia também nas políticas públicas, ajudando a ter mais conhecimento sobre o lugar, dando um suporte maior na elaboração de leis na região central.

\section{Referências}

PORTAL BRASIL. Economia. Setores da economia. 2010. Disponível em: <http://www.brasil.gov.br/sobre/ economia/setores-da-economia $>$. Acesso em: 1 maio 2011.

GOOGLE EARTH. Disponível em: <www.panoramio. com.photo>. Acesso em: 1 maio 2011. 
GRASSIOTTO, M. L. F. Espaços comerciais: a arquitetura em dois shopping centers de Londrina. 2000. Dissertação (Mestrado em Estruturas Ambientais Urbanas) - Faculdade de Arquitetura e Urbanismo, Universidade de São Paulo, São Paulo. 2000.

INSTITUTO BRASILEIRO DE GEOGRAFIA E ESTATÍSTICA - IBGE. Título. Disponível em: <http:// www.ibge.gov.br/cidadesat/topwindow.htm?1> Acesso em: 1 nov. 2010

INSTITUTO DE PESQUISA E PLANEJAMENTO URBANO DE LONDRINA - IPPUL. Plano Diretor de Londrina. Londrina: IPULL, 1997.

JACOBS, J. Morte e vida de grandes cidades. São Paulo: Martins Fontes, 2001.

JANUZZI, D. C. R. Avaliação de áreas públicas do centro da cidade de Londrina. 2000. Dissertação (Mestrado em Estruturas Ambientais Urbanas) Faculdade de Arquitetura e Urbanismo, Universidade de São Paulo, São Paulo. 2000.

VARGAS, H. C. Espaço terciário: o lugar, a arquitetura e a imagem do comércio. São Paulo: SENAC, 2001.

VILLAÇA, F. Espaço intra-urbano no Brasil. São Paulo: Studio Nobel, 1998.

VILLAÇA, F. Notas de Aula, tema: O Espaço Urbano e seu Planejamento. Mestrado Interinstitutional UEL/USP, 1999.

Recebido em 20 Junho 2011-Received on June 20, 2011.

Aceito em 23 Setembro, 2011 - Accepted on September 23, 2011. 